\title{
Effect of Revolution on Inhomogeneous Deformation of IF Steel in High Pressure Torsion
}

\author{
Yuepeng Song1,2,3*, Miaomiao Chen'1, Baoyan Xu1, Dongsheng Gao ${ }^{2}$, Hyoung Seop Kim ${ }^{3 *}$ \\ ${ }^{1}$ Shandong Agricultural University, Mechanical and Electronic Engineering College, Tai'an, China \\ ${ }^{2}$ Shandong Agricultural University, Shandong Provincial Key Laboratory of Horticultural Machineries and Equipments, Tai'an, China \\ ${ }^{3}$ Pohang University of Science and Technology, Department of Materials Science and Engineering, Pohang, Korea \\ Email: *uptonsong@163.com, *hskim@postech.ac.kr
}

How to cite this paper: Song, Y.P., Chen, M.M., Xu, B.Y., Gao, D.S. and Kim, H.S. (2016) Effect of Revolution on Inhomogeneous Deformation of IF Steel in High Pressure Torsion. Materials Sciences and Applications, 7, 673-679.

http://dx.doi.org/10.4236/msa.2016.711054

Received: September 8, 2016

Accepted: October 31, 2016

Published: November 3, 2016

Copyright (๑) 2016 by authors and Scientific Research Publishing Inc. This work is licensed under the Creative Commons Attribution International License (CC BY 4.0).

http://creativecommons.org/licenses/by/4.0/

\section{Abstract}

The effect of revolution on inhomogeneous plastic deformation of HPT processed IF steel was investigated using experimental and simulation approaches. The results indicate that the degree of inhomogeneous plastic deformation increases as the revolutions increase along the radial direction on the transversal plane of disks. In addition, the hardness and the microstructure distributions verify the trend that the effective strain of the HPT processed disks at the early torsion stage is gradually deformed from the edge to the center with the revolutions increases.

\section{Keywords}

High-Pressure Torsion, Inhomogeneous Deformation, IF Steel, Revolution, Finite Element Analysis

\section{Introduction}

In recent 20 years, the investigation on the micro-structural evolution of ultrafinegrained (UFG) materials surged tremendously due to outstanding characteristics of UFG materials, especially mechanical properties [1] [2] [3] [4]. Severe plastic deformation (SPD) processes have been used as convenient methods to manufacture ultrafinegrained, nanostructured metals and their alloys. Several SPD processes are used to manufacture UFG materials, including equal-channel angular pressing (ECAP), accumulative roll bonding (ARB), high-pressure torsion (HPT) and so on. Among these SPD methods, the HPT process is especially attractive because of its great potential to produce finer grains, with a higher fraction of high-angle grain boundaries [5]-[10]. 
The concept of the HPT process was first proposed over 70 years ago by Bridgman, but the process has been intensively investigated with respect to grain refinement within the last 10 years [5] [6] [7]. The process of HPT consists of two stages: compression stage and compression-torsion stage. In the first stage, high pressure is applied to a sample placed in between the top and bottom dies. In the second stage, the bottom die is rotated at the high pressure of upper die and a set rotational speed. A large amount of shear deformation is imposed on the disk by multiple rotations of the die during the torsion stage. During the HPT process, the heterogeneity of the deformation is affected by factors such as pressure, the number of revolutions, the coefficient of friction and so on, especially the number of revolutions.

Recent research mainly focuses on the degree of deformation under different conditions [11]-[16]. The results indicate that the deformation is more severe with the one of three factors increasing, including pressure, the number of revolutions and coefficient of friction [11] [12] [13] [14]. However, there is little literature on inhomogeneous deformation study of HPT processing [15] [16].

In this paper, the mainly factor of the number of revolutions on the inhomogeneous deformation of IF steel disks during the HPT process was investigated using FEM and experiments.

\section{Experimental and Simulation Procedures}

\subsection{Materials and Experimental Procedure}

In this work, IF steel was used as raw material for HPT process, which was manufactured by the Pohang Steel Company (POSCO, Korea) with the composition of 0.0026 wt\%C, $0.096 \mathrm{wt} \% \mathrm{Mn}, 0.045 \mathrm{wt} \% \mathrm{Al}$ and $0.041 \mathrm{wt} \% \mathrm{Ti}$. Cylindrical samples $(20 \mathrm{~mm}$ diameter, $2.0 \mathrm{~mm}$ thickness) were machined after annealing heat-treatment $\left(700^{\circ} \mathrm{C}\right.$ for 2 $\mathrm{h}$ followed by cooling in a furnace), resulted in sample grain size of $150-200 \mu \mathrm{m}$ and hardness of about $80 \mathrm{HV}$. Surface pressure of $2.5 \mathrm{GPa}$ was imposed on the disks at room temperature. The degree of revolutions during torsional stage were $0,1 / 4,2 / 4$, $3 / 4$, and 1turns, respectively.

An FM-700 micro-hardness tester was used to measure the hardness with pressure loading of $100 \mathrm{~g}$ for $10 \mathrm{~s}$. On the symmetric section of disks' thickness direction, the hardness is measured interval $0.5 \mathrm{~mm}$ distance from axial center to edge along with the radius direction. Micro-structures at different positions on the disks were observed using optical microscopy (Olympus U-TV0.5xc) taken from the disks after the HPT process.

\subsection{Simulation Procedure of DEFORM Code}

A commercial rigid-plastic finite element method (FEM) code (DEFORM-3D) was used to simulate the plastic deformation of IF steel disks in HPT process. In the FEM simulations, the initial dimensions of the disks were $20 \mathrm{~mm}$ diameter and $2.0 \mathrm{~mm}$ thickness. The number of the initial mesh in the sample was 25521 and this number of elements was enough to show the local deformation of the sample by calculation with- 
out changing the number of elements, as shown in Figure 1. All the strain data taken from DEFORM-3D code was processed using the Origin software for linear presentation, and the effective strain is calculated automatically based on Von-Mises yield criterion.

\section{Results and Discussion}

\subsection{Inhomogeneous Distributions of Effective Strain}

Figure 2 shows the effective strain distribution on the selected line and the effective strain distribution of half HPT processed IF steel disks (2.5 GPa; 0, 2/4, and 1 turns).
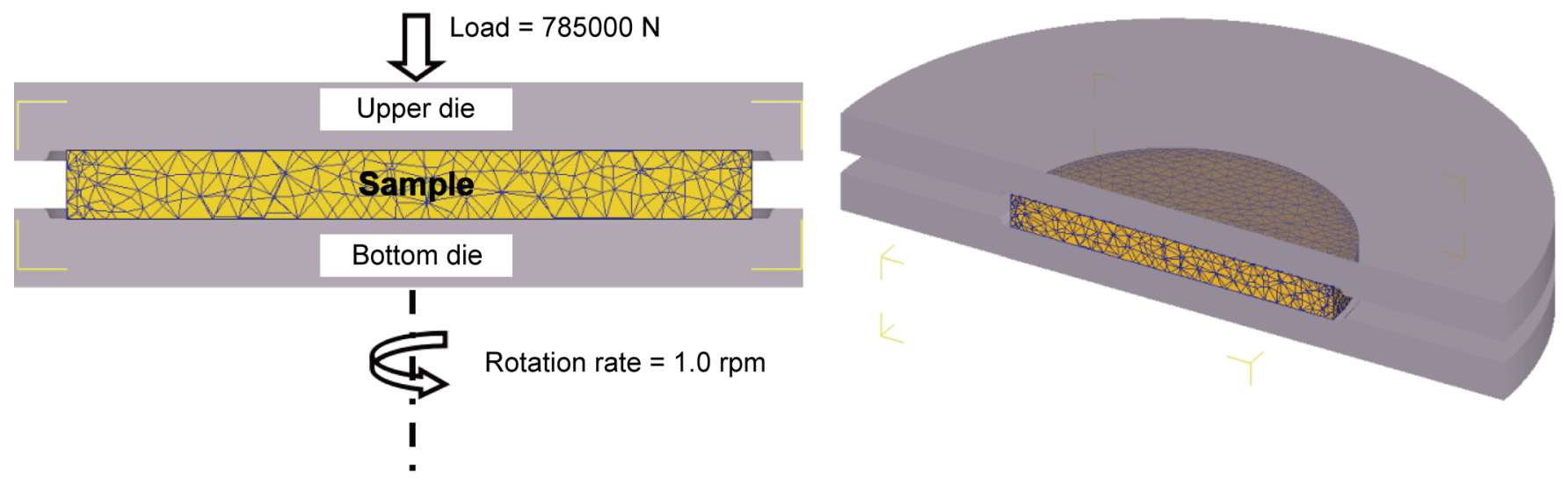

Figure 1. Illustration of the geometry of the dies and sample used in the simulation of quasi-constrained HPT processing.

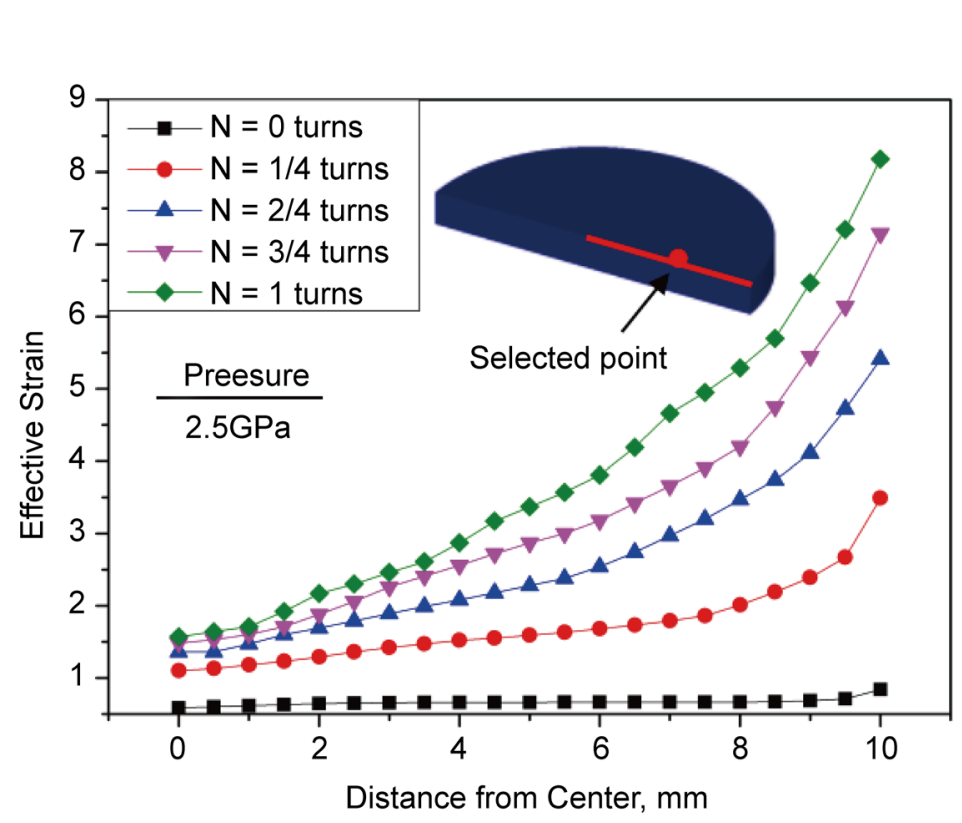

(a)

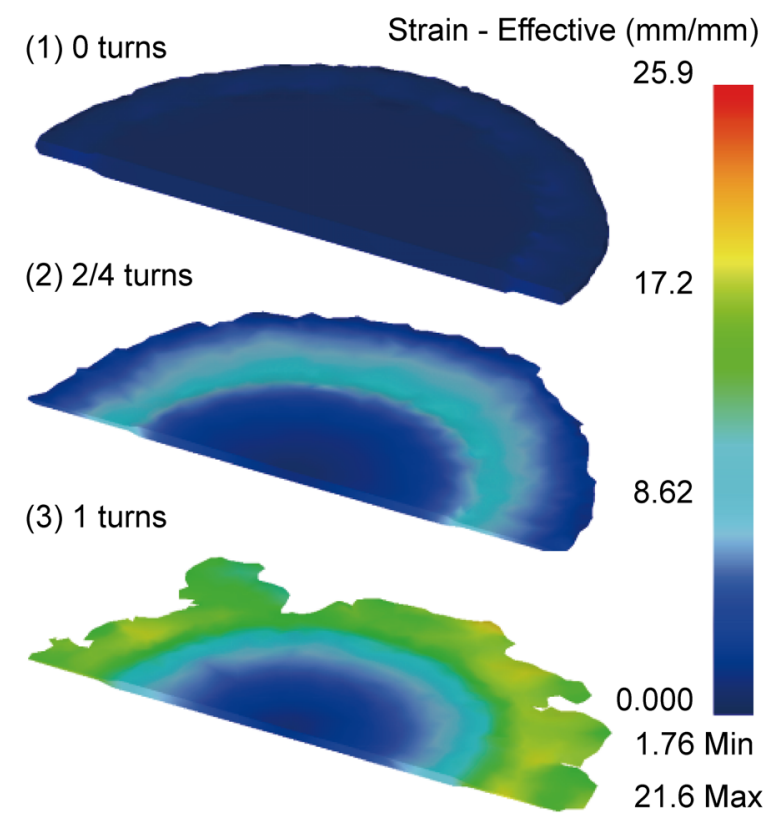

(b)

Figure 2. The effective strain distributions at different turns. (a) Path plots of effective strain on selected line; (b) Effective strain on half disks. 
The results clearly indicate that the degree of inhomogeneous deformation and the value of the effective strain increase as the revolutions increases, along the radial direction.

A line is selected near the surface to investigate the trend of effective strain along radial direction except the flying edge, as show in Figure 2(a). The results indicate that large deformation reduces gradually from the edge to the center along the radial direction at the early torsion stage of the HPT process due to the vertical wall constraint and the friction between disk and dies. In addition, the highest value of effective strain on the selected line increases from $\sim 0.84$ to $\sim 8.18$ with the revolutions increases to 1 turn. That means that, as the revolution increasing, the deformation of HPT processed disks is more inhomogeneous.

\subsection{Inhomogeneous Distributions of Hardness and Micro-Structures}

Hardness and micro-structure distributions on the transversal plane of the HPT processed IF steel disks (2.5 GPa; 0, 1/4, 2/4, 3/4 and 1 turns), as shown in Figure 3. The results indicates that the value of hardness is higher and the size of grain is smaller as number of revolution increasing, and the distributions of hardness and micro-structure are inhomogeneous.
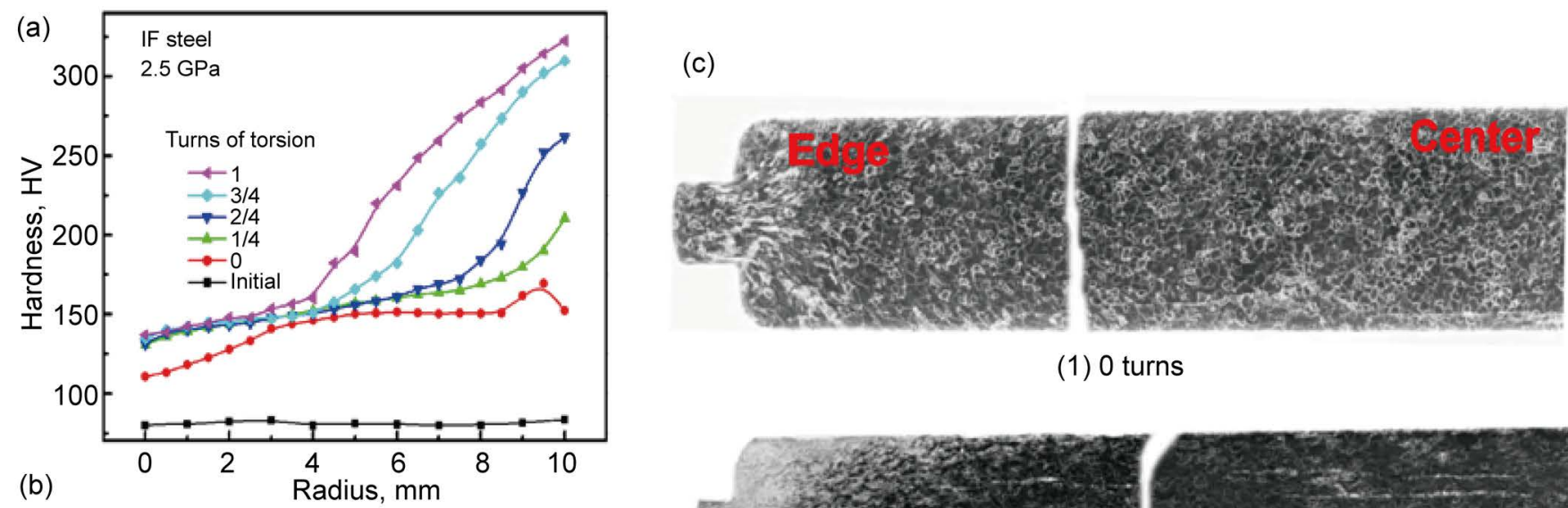

(1) 0 turns
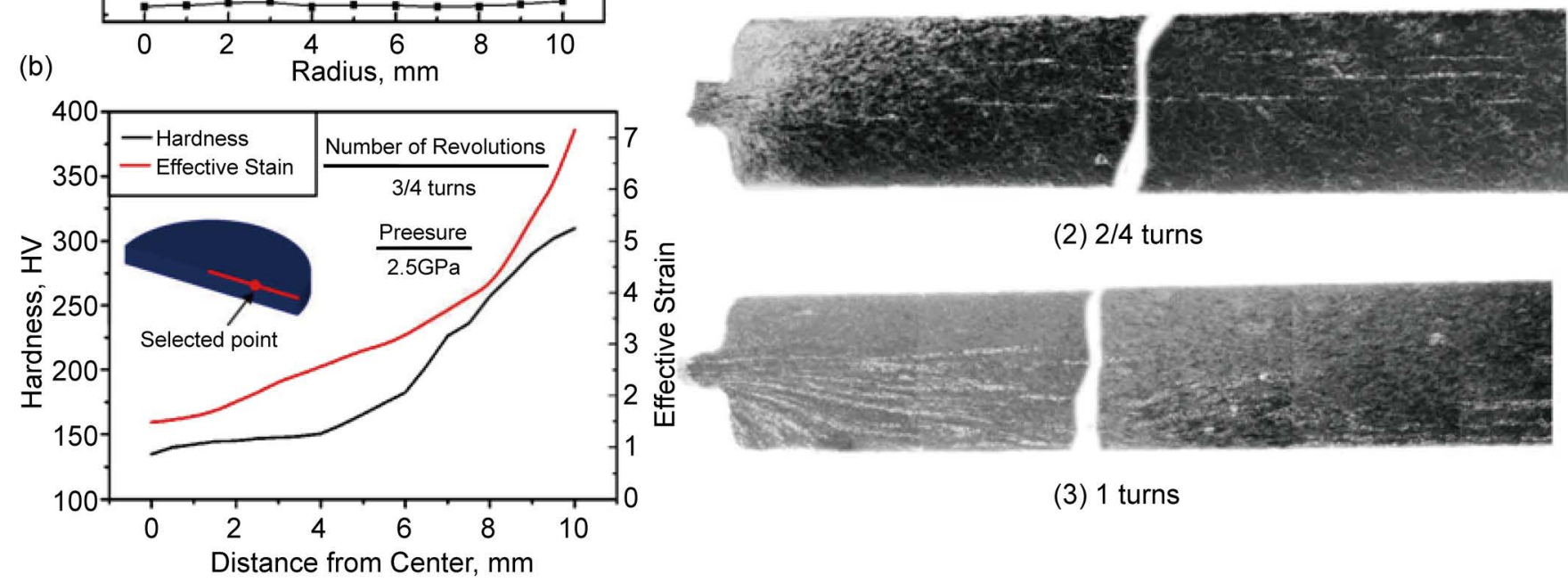

(2) $2 / 4$ turns

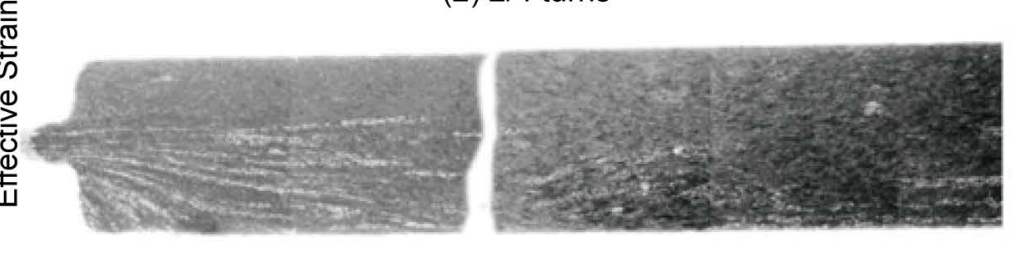

(3) 1 turns

Figure 3. Hardness and micro-structure distributions at different turns. (a) Hardness distribution; (b) Hardness-strain distribution; (c) Micro-structure distribution. 
As the Figure 3(a) shows, low hardness values in the center and high values at the edge: after 1 turn, the hardness values in the center, middle, and edge are 136.7, 189.6, 322.5 HV, respectively, exhibiting the same trend as in the literature [11] [17] [18]. In addition, the amplification of hardness from center to edge of disks is more and more big with the revolutions increase. Figure $3(\mathrm{c})$ clearly indicates that without torsional straining ( 0 turns), the grain boundaries are clearly observed and the grains are insufficiently equiaxed. In contrast, after an additional revolution in the same torsional direction to give 1 turn, the grain boundaries become obscure and the grains are reasonably equiaxed. That is to say, severe grain deformations and progressively larger deformation zone proceed gradually from the edge to the center with increasing the revolutions, which corresponds to the hardness distribution on the transversal testing plane. That means the micro-structure distribution of HPT processed disks is more inhomogeneous with the revolution increase, same as hardness distribution.

The hardness distribution of the experimentally compressed disks was reflected in the strain distribution of the simulations [19] [20]. Figure 3(b) provides a comparison between experimental hardness and simulation results of effective strain distribution in the compressed copper disk under the number of revolution of $3 / 4$ turns, applied pressure of $2.5 \mathrm{GPa}$. The same distribution trend was indicated in both experimental and simulated results. Hence, the reliability of this computer simulation is verified.

\section{Conclusions}

In this study, the effect of number of revolutions on inhomogeneous plastic deformation of HPT processed IF steel was investigated using experimental and simulation approaches. Inhomogeneous strain and variation in hardness (lower hardness in the center and higher hardness at the edge) exist on the transversal planes of disks.

The simulation results indicate that the degree of inhomogeneous effective strain increases as the revolutions increase, with the lower strain in center and higher strain in edge along the radial direction on the transversal plane of HPT processed IF steel disks. According to the experimental results, the hardness and the microstructure distributions have similar trend with the effective strain distribution of the HPT processed disks at the early torsion stage, while a gradual deformation from the edge to the center is more severe with the revolutions increases.

\section{Acknowledgements}

Y. P. Song acknowledges the postdoctoral fellowship supported by the National Research Foundation through the Korea-China Young Scientists Program, Korea. Furthermore, this work was also supported by Chinese National Fusion Project for ITER (NO. 2013GB110005), Innovation team fund for fruit industry of modern agricultural technology system in Shandong Province (SDAIT-06-12), Research project-2015 on intelligent agricultural mechanization equipment of Shandong Agricultural University, Special project for independent innovation of Shandong province (2013CXC90201). This work was supported by the National Research Foundation of Korea (NRF) grant 
funded by the Korea government (MSIP) (No. 2014R1A2A1A10051322).

\section{References}

[1] Xie, Z.L., Xie, J.J., Hong, Y.S. and Wu, X.L. (2010) Influence of Processing Temperature on Microstructure and Microhardness of Copper Subjected to High-pressure Torsion. Science China Technological Sciences, 53, 1534-1539. http://dx.doi.org/10.1007/s11431-010-3157-7

[2] Kim, H.S., Estrin, Y. and Bush, M.B. (2000) Plastic Deformation Behaviour of Fine-Grained Materials. Acta Materialia, 48, 493-504. http://dx.doi.org/10.1016/S1359-6454(99)00353-5

[3] Kim, H.S. and Estrin, Y. (2001) Ductility of Ultrafine Grained Copper. Applied Physis Letters, 79, 4115-4117. http://dx.doi.org/10.1063/1.1426697

[4] Xu, Ch., Horita, Z.J. and Langdon, T.G. (2008) The Evolution of Homogeneity in an Aluminum Alloy Processed Using High-Pressure Torsion. Acta Materialia, 56, 5168-5176. http://dx.doi.org/10.1016/j.actamat.2008.06.036

[5] Zhilyaev, A.P. and Langdon, T.G. (2008) Using High-Pressure Torsion for Metal Processing: Fundamentals and Applications. Progress in Materials Science, 53, 893-979. http://dx.doi.org/10.1016/j.pmatsci.2008.03.002

[6] Figueiredo, R.B., Aguilar, M.T.P., Cetlin, P.R. and Langdon, T.G. (2011) Deformation Heterogeneity on the Cross-Sectional Planes of a Magnesium Alloy Processed by HighPressure Torsion. Metallurgical and Materials Transactions A, 42, 3013-3021. http://dx.doi.org/10.1007/s11661-011-0609-Z

[7] Hohenwarter, A., Bachmaier, A., Gludovatz, B., Scheriau, S. and Pippan, R. (2009) Technical Parameters Affecting Grain Refinement by High Pressure Torsion. International Journal of Materials Research, 100, 1653-1661. http://dx.doi.org/10.3139/146.110224

[8] Zhilyaev, A.P., Oh-ishi, K., Langdon, T.G. and McNelley, T.R. (2005) Microstructural Evolution in Commercial Purity Aluminum during High Pressure Torsion. Materials Science and Engineering A, s410-s411, 277-280.

[9] Edalati, K., Fujioka, T. and Horita, Z. (2008) Microstructure and Mechanical Properties of Pure $\mathrm{Cu}$ Processed by High-pressure Torsion. Materials Science and Engineering A, s1-s2, 168-173.

[10] Kim, H.S., Ryu, W.S., Janecek, M., Baik, M. and Estrin, Y. (2005) Effect of Equal Channel Angular Pressing on Microstructure and Mechanical Properties of IF Steel. Advanced Engineering Materials, 7, 43-46. http://dx.doi.org/10.1002/adem.200400146

[11] Hebesberger, T., Stuwe, H.P., Vorhauer, A., Wetscher, F. and Pippan, R. (2005) Structure of Cu Deformed by High Pressure Torsion. Acta Materialia, 53, 393-402.

http://dx.doi.org/10.1016/j.actamat.2004.09.043

[12] Song, Y.P., Wang, W.K., Gao, D.S., Yoon, E.Y., Lee, D.J., Lee, Ch.S. and Kim, H.S. (2013) Hardness and Microstructure of Interstitial Free Steels in the Early Stage of High-Pressure Torsion. Journal of materials science, 48, 4698-4705. http://dx.doi.org/10.1007/s10853-012-7031-9

[13] Song, Y.P., Wang, W.K., Gao, D.S., Yoon, E.Y., Lee, D.J. and Kim, H.S. (2014) Finite Element Analysis of the Effect of Friction in High Pressure Torsion. Metals and Materials International, 20, 445-450. http://dx.doi.org/10.1007/s12540-014-3007-4

[14] Song, Y.P., Yoon, E.Y., Lee, D.J., Lee, J.H. and Kim, H.S. (2011) Mechanical Properties of Copper after Compression Stage of High-Pressure Torsion. Materials Science and Engineering $A$, 582, 4840-4844. http://dx.doi.org/10.1016/j.msea.2011.02.020

[15] Sakai, G., Nakamura, K., Horita, Z. and Langdon, T.G. (2005) Developing High-Pressure 
Torsion for Use with Bulk Samples. Materials Science and Engineering A, 406, 268-273. http://dx.doi.org/10.1016/j.msea.2005.06.049

[16] Song, Y.P., Wang, W.K., Lee, D.J., Jeong, H.J., Lee, S. and Kim, H.S. (2015) Thickness Inhomogeneity in Hardness and Microstructure of Copper after the Compressive Stage in High-pressure Torsion. Metals and Materials International, 21, 7-13.

http://dx.doi.org/10.1007/s12540-015-1002-z

[17] Xu, Ch., Horita, Z.J. and Langdon, T.G. (2007) The Evolution of Homogeneity in Processing by High-Pressure Torsion. Acta Materialia, 55, 203-212.

http://dx.doi.org/10.1016/j.actamat.2006.07.029

[18] Estrin, Y., Molotnikov, A., Davies, C.H.J. and Lapovok, R. (2008) Strain Gradient Plasticity Modelling of High-Pressure Torsion. Journal of the Mechanics \& Physics of Solids, 56, 1186-1202. http://dx.doi.org/10.1016/j.jmps.2007.10.004

[19] Lee, D.J., Yoon, E.Y., Park, L.J. and Kim, H.S. (2012) The Dead Metal Zone in HighPressure Torsion. Scripta Materiallia, 67, 384-387.

[20] Lee, D.J. and Kim, H.S. (2014) Finite Element Analysis for the Geometry Effect on Strain. Journal of Materials Science, 49, 6620-6628. http://dx.doi.org/10.1007/s10853-014-8283-3

\section{Submit or recommend next manuscript to SCIRP and we will provide best service} for you:

Accepting pre-submission inquiries through Email, Facebook, LinkedIn, Twitter, etc.

A wide selection of journals (inclusive of 9 subjects, more than 200 journals)

Providing 24-hour high-quality service

User-friendly online submission system

Fair and swift peer-review system

Efficient typesetting and proofreading procedure

Display of the result of downloads and visits, as well as the number of cited articles

Maximum dissemination of your research work

Submit your manuscript at: http://papersubmission.scirp.org/

Or contact msa@scirp.org 